\title{
Evaluation Study on the Operation Ability of Urban Old-age Care Service Institutions Based on Principal Component Analysis
}

\author{
Zhen Shi ${ }^{1}$ \\ ${ }^{1}$ School of Management, Shanghai University of Engineering Science, Shanghai, China \\ Correspondence: Zhen Shi, School of Management, Shanghai University of Engineering Science, Shanghai, ON., \\ Long Teng Road No.333, China. Tel: 86-138-1678-7444. E-mail: shizhen_8023@126.com
}

This work was supported by Research on the Effectiveness of Urban Pension Agency Resource Allocation. (A-0903-13-01062).

Received: December 5, 2013 Accepted: December 18, 2013 Online Published: December 21, 2013

doi:10.5430/sass.v1n1p48 URL: http://dx.doi.org/10.5430/sass.v1n1p48

\begin{abstract}
The increasingly intensified trend of aging population requires to accelerate the construction of social old-age service system. The development of urban old-age service institutions has become an urgent issue that needs to be solved. Referring to the related national policies, standards and existing research achievements and on the basis of Principal Component Analysis method, the author selects nine indicators to evaluate and study the operation ability of old-age service institutions among 12 districts of Shanghai City, hoping to provide a reference for the future development of old-age service institutions.
\end{abstract}

Keywords: old-age care service, Principal Component Analysis, institutions evaluation, operation ability

\section{Introduction}

Population aging is an inevitable product of human and social development, the increase of which has exerted a comprehensive and far-reaching effect on the society. Shanghai, a city with the largest amount of aging population, is the first in China to enter into the population aging stage. By the end of 2011, Shanghai has 3,477,600 people aged 60 or older, accounting for $24.5 \%$ of the total population, while 629,200 people aged 80 or older which accounts for $18.81 \%$ of 60 -plus population. It is estimated that the population aged 60 or more with Shanghai domicile will be over 4,300,000 and the proportion will get close to reach $30 \%$ at the end of 2015 .In the meantime, it has become the focus of social policies made by governments at all levels to provide necessary guarantee and service to the aging population. Indicated in the Eleventh Five-Plan on the Development of Shanghai Civil Affair (No.3, [2007], Shanghai) that, efforts should be made to construct an old-age welfare service system in accordance with the aging population, forming an old-age pattern that focuses on the home care for the aged and assists by the institutions. In recent years, old-age care institutions of various forms have obtained significant growth as well as various problems, such as the unbalance between supply and demand, and their poor operation. On the one hand, from the perspective of quantity, these old-age care institutions generally have a shortage of beds; on the other hand, in accordance with the location distribution, the old-age care institutions do not have sufficient supply in the downtown area, while those in the suburban area have beds in idle. At the same time, there are many problems existing in the current operation of old-age care institutions, among which, inadequate personnel allocation, low staff quality and low profitability of the institution are common problems faced by the old-age care institutions. These conditions will not benefit the healthy and fast development of old-age care institutions.

The management and operation of Pension institutions is an important part in the construction and management of Public resources, and it is also a topic which must be dealt with in the progress of social development. Strengthening the research on the operation of Pension institutions helps to construct effective social security system and meets the requirement of aging society development.Evaluation study on the operation ability of old-age service institutions can help integrate the social public service resources and improve the utilization rate of social public resources. Therefore, referring to the related national policies, standards and existing research achievements and on the basis of Principal Component Analysis method, the author selects nine indicators to evaluate and study the operation ability 
of old-age service institutions among 12 districts of Shanghai City, hoping to provide a reference for the future development of old-age service institutions.

\section{Use of Principal Component Analysis}

\subsection{The Principle of PCA}

Principal component analysis (PCA) is a statistical procedure that uses orthogonal transformation to convert a set of observations of possibly correlated variables into a set of values of linearly uncorrelated variables called principal components. The number of principal components is less than or equal to the number of original variables. This transformation is defined in such a way that the first principal component has the largest possible variance (that is, accounts for as much of the variability in the data as possible), and each succeeding component in turn has the highest variance possible under the constraint that it be orthogonal to (i.e., uncorrelated with) the preceding components. Principal components are guaranteed to be independent if the data set is jointly normally distributed. PCA is sensitive to the relative scaling of the original variables.

\subsection{Selection for Indicators}

The old-age care service institution refers to a comprehensive service institution that provides service to the aged on various aspects, such as "diet and daily life, sanitation and hygiene, life care, health management and entertainment". By referring to the previous research achievements, in accordance with various standard documents such as Management Methods for Shanghai Old-age Care Institutions, Standard of Building Design of Old-age Care Facilities and Personnel Allocation Standard of Shanghai Old-age Care Institutions, the author believes that the main factors that impact the operation of old-age care service institutions in Shanghai include the input scale, employee quality and capital scale of old-age care service institutions. Since some data cannot be collected during the empirical process, the author uses related indicators as the alternative, for example, the number of old-age care service institutions, the number of bed at the end of the year, floorage, the total number and duration of old people in the institution every year replacing the input scale of old-age care service institutions, the number of selected young employees (under 35) and the employee quality indicated by the employees with a college education or above. As non-profit service institutions, the old-age care service institutions highlights the characteristics as public welfare, in addition to some general industrial characteristics. Therefore, the old-age care service institution implements the accounting system for non-governmental non-profit organizations to fill its annual income and expenses, which is used to describe the capital scale.

In this paper, there are 9 indicators chosen as the indicator system of Pension institutions operational capability evaluation.Evaluation index from X1 X9 are presented in Table 1.The related symbols are shown as below.

Table 1. Evaluation index of operation ability of old-age care service institutions in Shanghai

\begin{tabular}{|c|c|c|c|}
\hline $\begin{array}{l}\text { Target } \\
\text { Level }\end{array}$ & \multicolumn{3}{|c|}{ The operation ability of old-age care service institutions in Shanghai City } \\
\hline \multirow{9}{*}{$\begin{array}{l}\text { Index } \\
\text { Level }\end{array}$} & \multirow{5}{*}{ Input Scale } & The number of old-age care service institutions & $\mathrm{X} 1$ \\
\hline & & The bed number at the end of the year & $\mathrm{X} 2$ \\
\hline & & Floorage of old-age care institutions & $\mathrm{X} 3$ \\
\hline & & Duration of the total number of old people in the institution every year & $\mathrm{X} 4$ \\
\hline & & Crew size of year end & X5 \\
\hline & \multirow{2}{*}{$\begin{array}{l}\text { Employee } \\
\text { Quality }\end{array}$} & The number of young employees & $\mathrm{X} 6$ \\
\hline & & The employees with a college education or above & $\mathrm{X} 7$ \\
\hline & \multirow{2}{*}{$\begin{array}{l}\text { Capital } \\
\text { Scale }\end{array}$} & $\begin{array}{l}\text { Annual income of the accounting system of non-governmental } \\
\text { non-profit organizations }\end{array}$ & $\mathrm{X} 8$ \\
\hline & & $\begin{array}{l}\text { Annual expenses of the accounting system of non-governmental } \\
\text { non-profit organizations }\end{array}$ & $\mathrm{X} 9$ \\
\hline
\end{tabular}

At first, the author chose 17 districts and counties of Shanghai as the research objects, but considering the integrity of related data, Fengxian District, Qingpu District, Songjiang District, Hongkou District and Chongming xian were eliminated, and the rest 12 districts were reserved as the research objects, which are distributed in to downtown area, 
the expanded area and suburban area of Shanghai City respectively. The data of related variables come from the China Civil Affairs Statistic Yearbook-2012 Appendix of China's Economic and Social Development Statistical Database.

\subsection{Analysis Procedure}

We generally choose the factors with an accumulating contribution rate $>85 \%$ as the principal components. In accordance with Table 2, we can see that the eigenvalues of the previous principal components are both bigger than 1 , and their accumulating contribution rate is $95.711 \%$, so they are suitable to be used in the principal component analysis.

Table 2. Total Variance Explained

\begin{tabular}{|c|c|c|c|c|c|c|c|c|c|}
\hline \multirow[b]{2}{*}{ Component } & \multicolumn{3}{|c|}{ Initial Eigenvalues } & \multicolumn{3}{|c|}{ Extraction Sums if Squared Loadings } & \multicolumn{3}{|c|}{\begin{tabular}{|llll} 
Rotation & Sums & if & Squared \\
Loadings & & & \\
\end{tabular}} \\
\hline & Total & $\begin{array}{l}\% \\
\text { Variance }\end{array}$ & $\begin{array}{l}\text { of Cumulative } \\
\%\end{array}$ & Total & $\begin{array}{l}\% \\
\text { Variance }\end{array}$ & Cumulative \% & Total & $\begin{array}{l}\% \\
\text { Variance }\end{array}$ & $\begin{array}{l}\text { of Cumulative } \\
\%\end{array}$ \\
\hline 1 & 6.591 & 73.235 & 73.235 & 6.591 & 73.235 & 73.235 & 6.031 & 67.016 & 67.016 \\
\hline 2 & 2.023 & 22.476 & 95.711 & 2.023 & 22.476 & 95.711 & 2.583 & 28.695 & 95.711 \\
\hline 3 & .317 & 3.521 & 99.232 & & & & & & \\
\hline 4 & .039 & .434 & 99.666 & & & & & & \\
\hline 5 & .016 & .178 & 99.844 & & & & & & \\
\hline 6 & .009 & .097 & 99.941 & & & & & & \\
\hline 7 & .003 & .037 & 99.978 & & & & & & \\
\hline 8 & .002 & .018 & 99.996 & & & & & & \\
\hline 9 & .000 & .004 & 100.000 & & & & & & \\
\hline
\end{tabular}

Through the analysis of the rotating factor loading matrix,we can see:X1、X2、X3、X4、X5 and X6 are synthesized as the first principal component.The general character of these indicators is the most important symbol that reflects the institution's operation ability - the institution's scale, which is also closely related to the institution's infrastructural construction, so it is named as infrastructural scale factor. This main factor has the biggest variance contribution, which reaches $67.016 \%$, so the scale of old-age care infrastructure and human resource input of various districts are the most important to the operation of old-age care service institutions.

The second principal component has three indicators(X7、X8 and X9), which is named as operation ability factor. This main factor has the second biggest variance contribution, which reaches $28.695 \%$, so implementation of the unit accounting system of non-governmental non-profit organization to fill its annual income and expenses and the number of high-quality talents are also very important to the operation of urban old-age care service institutions in Shanghai.

Table 3. Component Score Coefficient Matrix

\begin{tabular}{|l|l|l|}
\hline \multirow{2}{*}{} & \multicolumn{2}{|l|}{ Component } \\
\cline { 2 - 3 } & 1 & 2 \\
\hline Zscore $(\mathrm{X} 1)$ & 160 & -.002 \\
\hline Zscore $(\mathrm{X} 2)$ & .179 & -.062 \\
\hline Zscore $(\mathrm{X} 3)$ & .186 & -.088 \\
\hline Zscore $(\mathrm{X} 4)$ & .157 & .009 \\
\hline Zscore $(\mathrm{X} 5)$ & .139 & .061 \\
\hline Zscore $(\mathrm{X} 6)$ & .191 & -.111 \\
\hline
\end{tabular}




\begin{tabular}{|l|l|l|}
\hline Zscore (X7) & -.141 & .420 \\
\hline Zscore (X8) & -.012 & .343 \\
\hline Zscore (X9) & -.028 & .362 \\
\hline
\end{tabular}

Expressions of two main components can be drawn according to the feature vector in the factor score matrix. The first principal component function is $\mathrm{Z1}=-0.16 \mathrm{X} 1+0.179 \mathrm{X} 2+0.186 \mathrm{X} 3 \quad+0.157 \mathrm{X} 4$ $+0.139 \times 5+0.191 \times 6-0.141 \times 7-0.012 \times 8-0.028 \times 9$. The second principal component function is $\mathrm{Z} 2=-0.002 \mathrm{X} 1-0.062 \times 2-0.088 \times 3-0.009 \times 4-0.061 \times 5-1.11 \times 6+0.42 \times 7+0.343 \times 8+0.362 \times 9$.

Factor comprehensive score is $\mathrm{Z}=(67.016 \mathrm{Z} 1+28.695 \mathrm{Z} 2) / 95.711$

Import the collected corresponding records and calculate the principal component scores and comprehensive scores, as shown in Table 4.

Table 4. Evaluation index of operation ability of old-age care service institutions in Shanghai

\begin{tabular}{|l|l|l|l|l|l|l|}
\hline District & $\begin{array}{l}\text { Comprehensive } \\
\text { Scores }\end{array}$ & Ranking & $\begin{array}{l}\text { Factor1 } \\
\text { Scores }\end{array}$ & Ranking & $\begin{array}{l}\text { Factor2 } \\
\text { Scores }\end{array}$ & Ranking \\
\hline $\begin{array}{l}\text { Pudong } \\
\text { New }\end{array}$ & 1.97353914 & 1 & 3.100449475 & 1 & $\begin{array}{l}-0.3633318 \\
7\end{array}$ & 7 \\
\hline Yangpu & 0.783835318 & 2 & 0.04439615 & 2 & $\begin{array}{l}2.62792401 \\
1\end{array}$ & 1 \\
\hline Xuhui & 0.150428338 & 3 & -0.353619572 & 7 & $\begin{array}{l}1.35009594 \\
1\end{array}$ & 2 \\
\hline Putuo & 0.00951337 & 4 & -0.02371163 & 3 & 0.08853094 & 3 \\
\hline Huangpu & -0.07353912 & 5 & -0.058697255 & 4 & -0.11919348 & 4 \\
\hline Zhabei & -0.121974 & 6 & -0.078080982 & 5 & -0.2427156 & 5 \\
\hline $\begin{array}{l}\text { Changnin } \\
\text { g }\end{array}$ & -0.27150592 & 7 & -0.160175542 & 6 & -0.5720950 & 11 \\
\hline Minhang & -0.42285396 & 8 & -0.445772235 & 8 & -0.4325326 & 8 \\
\hline Baoshan & -0.44528399 & 9 & -0.521364263 & 12 & -0.3341575 & 6 \\
\hline Jing'an & -0.47474292 & 10 & -0.485071412 & 9 & -0.5215803 & 9 \\
\hline Jiading & -0.50692337 & 11 & -0.51572549 & 11 & -0.5621354 & 10 \\
\hline Jinshan & -0.60049289 & 12 & -0.502627243 & 10 & -0.9188089 & 12 \\
\hline
\end{tabular}

According to the score of principal component, the author makes a scatter diagram with Factor 1 as ordinate against Factor 2 as abscissa in order to give a more intuitive graphical analysis, as shown in Figure 1. 


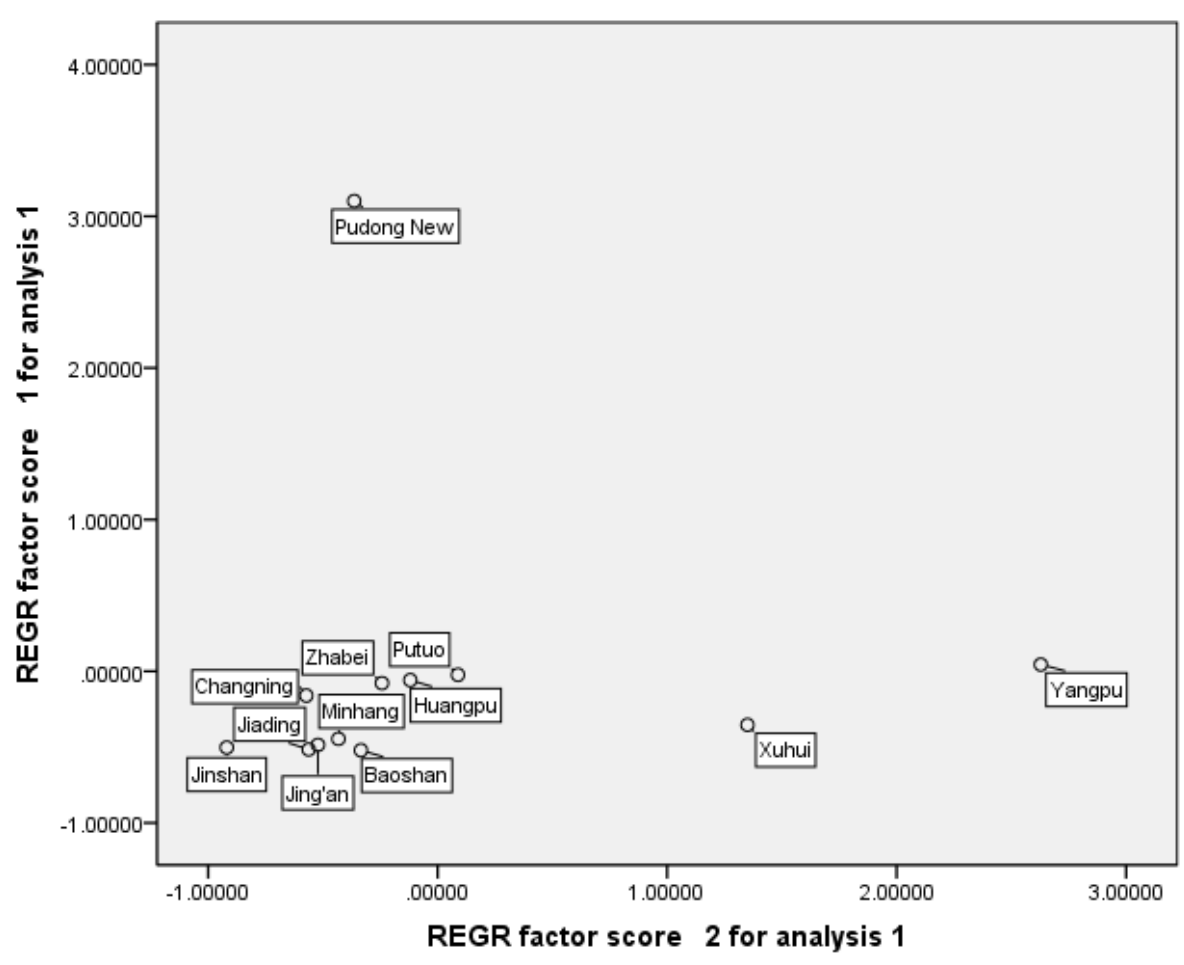

Figure 1.

According to the scatter diagram, Pudong New District gets the highest score in infrastructural scale factor, followed by the Yangpu District, Putuo District, Huangpu District. Three districts with the lowest scores are Baoshan District, Jiading District and Jinshan District. Yangpu District gets the highest score in operation ability factor, followed by Xuhui District, Putuo District and Huangpu District. Three districts with the lowest scores are Jinshan District, Changning District, Jiading District.

\subsection{Evaluation and Analysis}

Firstly, from the comprehensive scores and rankings of factors in various samples, we can learn that the operation abilities of various old-age care service institutions are in different levels obviously, which can be divided into three groups. The first group includes Pudong New District, Yangpu District and Xuhui District, who share a common point that, the scale indicators, the number of old-age service institutions, the number of bed and floorage, take the comparative advantage. Pudong District, especially, enjoys an overwhelming superiority in the number of old-age care service institutions for its large area and rich land resources.In 2009, because Nanhui District was merged into Pudong New District, the area of this district has expanded rapidly, which now covers 1,210 square kilometers. However, the reason of the top comprehensive ranking of old-age care service institutions in this area is that it is under the common impact of various factors, such as the economic, population, land cost and environment factors. The construction of old-age care service institutions is based on economic development, so in areas with good economic conditions, the usage rate of bed in old-age care institutions is relatively higher, and the institutions' operation situation is also better. In addition to the balanced distribution of old-age care institutions operated by government within various districts and counties, the private old-age care institutions focus more on the profitability, so they will choose the sections with good economic condition, higher service needs and lower land cost. Therefore, Pudong New District has been the aggregation of old-age care service institutions. For the same reason, although Jiading District and Jinshan District have land cost advantages, their economic development is not as good as the Pudong New District, and the old people in suburban area do not have adequate requirement for services, so they rank the lowest in comprehensive indicators.

The second group, whose comprehensive score ranks in the middle, includes six districts including Putuo District, Huangpu District, sharing a common characteristic that they are all in the downtown area or expanded area with high 
level of economic development but limited supply of land resource, so the input scale and operation ability of their old-age care service institutions cannot be fully carried out.

The third group includes Jing'an, Jiading and Jinshan Districts. Jiading and Jinshan Districts locate in the suburban area with relatively backward economic development, and the old in this area, who prefer the family support, are different in choosing old-age care patterns from those in the downtown area. Therefore, the input scale of old-age care service facilities in these two districts is not as large as that in the first two groups. That Jing'an District enjoys the best geographical location while it is divided into the third group is mainly due to its scarce land resource, which leads to its lower number of institutions and bed than other districts in the downtown area.

Secondly, from the perspective of the first component, we learn that the rankings of various districts are basically consistent with their comprehensive rankings, which means the institution's operation ability is mainly affected by the infrastructure construction. Compared to the suburban area, the rankings of districts in the downtown area are generally among the top, which is closely related to the residents' income level, the high concentration of old people, convenient transportation and good cultural environment.

Last but not the least, selection of different evaluation indicators has significant impact on the evaluation results, and the districts with high comprehensive rankings do not necessary have high rankings on various components, which is especially significant on the second component. It reflects that the construction of old-age care service institutions should not only purse the increase in quantity and scale, but also emphasize improvement of operation ability. Besides to offer enough hardware facilities, efforts should also be made to encourage high-quality talents to participate into the management and construction of old-age care service institutions, the operation ability of old-age care service institutions should be improved through the carrier of human resource, scale operation of the institution should be formed, and efforts should be made to realize the final improvement of economic benefits and service potential.

\section{Suggestion}

The research results show that the various indicators of urban pension services run ability all have different degrees of influence.In order to change the current situation of unbalanced supply and poor operation, the above multiple factors must be considered comprehensively. Based on that, the author puts up some pieces of suggestions on the following two aspects:

(I) The old-age care service institutions should improve the old-age care service level by increasing the input of hardware facilities and employee number in order to attract more senior citizens to buy the old-age care services.

The result of empirical analysis shows that the six key indicators of basic scale factors are the most important influencing factors on the operation ability of urban old-age care service institutions, which can reflect the scale and service level of old-age care service institutions. At present, the old-age care service institutions should increase the input of fixed assets, increase the employee number and provide professional training to the employees, and in this way, they can meet their requirements on various aspects such as physiology and psychology when providing services to the old people, improve the level of old-age care service and attract more senior citizens to choose the old-age care service institutions. Therefore, the old-age care service institutions can form scale effect during the operation, which can effectively relieve the operation pressure of old-age care service institutions. The author believes that only by intensifying both hardware and software construction, can the old-age care service institutions realize sustainable development.

(II) The government should make efforts to develop economy, improve the income level of urban residents especially suburban residents, and increase the input on the old-age care service institutions.

The income level decides the senior citizens' ability to buy old-age care services. Old people generally have a low income level, so their ability to buy old-age care services is relatively weaker, which has caused the situation of high requirement while low occupancy rate during the operation process of old-age care service institutions. For urban senior citizens, especially for suburban senior citizens, even if they choose the old-age care services with low standard, many are still unable to afford the expenses to live in an old-age care service institution, and finally, they have to choose other patterns of old-age care. Therefore, the government should make efforts to develop economy and improve the income level of citizens, so that more senior citizens will be able to buy old-age care services. In addition, because of the huge operation pressure faced by the old-age care service institutions, the state should also increase the input on the old-age care service institutions within the financial ability, reduce the operation cost of old-age care service institutions by providing tax breaks, reduce the survival pressure and operation risks of old-age care service institutions, and increase their profits. 


\section{References}

Jiang X. Q., Ding Z. H., \& Qin Y. Y. (2011). A multivariate analysis of the development of China's pension agency. Population \& Economics, 4, 58-69.

Jolliffe I. T. (2002). Principal Component Analysis. Series: Springer Series in Statistics (2nd ed.), Springer, NY, XXIX, 487, p. 28, illus. ISBN 978-0-387-95442-4.

Liu J., \& Shu S. L. (2013). The empirical research on the impact factors of aged support agencies in China. Academy of Management Journal, 2, 58-62.

Xue, Q. (2013). Evaluation study on the developing situation of elderly welfare institutions in China based on Principal Component Analysis. The world of labor security, 2, 22-23. 